\title{
Evaluation of Clinico-Pathological Study of Breast Cancer in Rural Population
}

\author{
Dr Narayan Das ${ }^{1}$, Dr Anarsh Debbarma ${ }^{2}$, Dr Anup kumar Saha ${ }^{3}$, \\ ${ }^{I}$ M B B S, M S (General Surgery), Assistant Professor, Department of surgery, Agartala Government Medical \\ college \& G B P Hospital, Agartala Tripura (West),799006. \\ ${ }^{2} M$ B B S, MS (General Surgery), Registrar, Department of Surgery, Agartala Government Medical College \& \\ G B P Hospital, Agartala, Tripura (West), 799006. \\ ${ }^{3}$ M B B S , MS (General Surgery), Prof \& HOD, Department of Surgery, Agartala Government Medical \\ College \& G B P Hospital, Agartala, Tripura (West)799006.
}

\begin{abstract}
Background and Objectives : Breast cancer is the second most common cancer in the Indian female population. As per our hospital data, breast cancer is also to be the second leading malignancy in women. Hence, we undertook this study to evaluate the clinical profile and histological types of breast cancer in our patients. Majority of our patients are from rural areas.

Materials and Methods: The study was undertaken for a period of four years from January 2012 to December 2015 comprising of one hundred female patients who were treated in the department of Surgery at Agartala Government Medical College \& G B P Hospital, Agartala . Diagnosis were made by a combination of clinical assessment, radiological imaging and tissue biopsy the so- called triple assessment .

Results: The commonest presentation of cancer of breast was breast lump. The commonest age group of breast cancer ranged from 41 years to 60 years. The most common site of tumor was the upper outer quadrant of breast and infiltrating ductal carcinoma (IDC) was the most common histologic type of breast cancer in our society.

Conclusion: The incidence of breast cancer in India is increasing and basic education and awareness of the women's health, self breast examination, and clinical breast examination may help increasing awareness and help to identify breast cancer at early stage in developing countries.
\end{abstract}

Keywords: Breast cancer, clinical profile, histopathology.

\section{Introduction}

Breast cancer is the most common form of cancer in women and listed as second leading cause of cancer death among women (1). Breast cancer contributes for 5-8\% of all cancer in India (2), and there is a rising trend in its incidence (3). Every year 75,000 new cases of breast cancer are diagnosed in Indian women (4). The probability of developing breast cancer during lifetime in Indian women is 1 in 22 as compared to 1 in 8 women in the United States and other developed countries (5). Genetic differences, the stage of disease at the time of diagnosis, availability of proper and appropriate care are some of the factors which explain the differences in incidence, clinical profile and outcome of the patients (6). The present study describes the clinical profile and histopathology of breast cancer in rural population .

\section{Materials and Methods}

This study was conducted in the department of surgery at Agartala government medical college \& G B P hospital , Agartala from January 2012 to December 2015.

The one hundred women were treated for breast cancer were included in this study

Inclusion Criteria: Female patients with diagnosed breast cancer were included in this study .

Exclusion Criteria: Women with history breast cancer who had been operated earlier for breast cancer and on preoperative chemotherapy or radiotherapy and recurrence cases and male breast cancer were excluded in this study . A detailed history of all one hundred cases was taken according to a detailed proforma. Diagnosis was made by a combination of clinical assessment, radiological imaging and tissue sample taken for cytological or histological analysis, the so-called triple assessment .

\section{Results}

This study included a total of one hundred cases that were studied prospectively in the department of surgery at Agartala government medical college \& G B P hospital, Agartala . The age of the patients of breast cancer ranged from 29 years to 64 years. The majority of the patients are in the age group of 41 years to 60 years (Table 1). All of the patients presented was that of a lump, with slightly left side dominance (Table 2). 
Upper outer quadrant of the breast was the site of lump in more than half of patients (Table 3). Most of the patients presented in stage II / III (Table4). Infiltrating ductal carcinoma was the most common histological type $(85 \%)$ followed by infiltrating lobular carcinoma (8\%) (Table 5). The most common treatment offered was modified radical mastectomy with referral to oncologist at regional cancer centre ( R C C), Agartala for adjuvant chemotherapy and radiotherapy. Very few patients came for follow-up i.e about $10 \%$ of cases . Two patients that come for follow-up had recurrence. The common site of recurrence was in the operated breast .

Table 1: Age- wise distribution of breast cancer.

\begin{tabular}{|lccccc|}
\hline Diagnosis & Age & Age & Age & Age & Age \\
\hline & (Year) & (year) & (year) & (year) & (year) \\
\hline & $21-30$ & $31-40$ & $41-50$ & $51-60$ & $61-70$ \\
\hline Carcinoma breast & 1 & 4 & 48 & 46 & 1 \\
\hline Percentage & $1 \%$ & $4 \%$ & $48 \%$ & $46 \%$ & $1 \%$ \\
\hline
\end{tabular}

Table2: Involvement of breast carcinoma .

\begin{tabular}{|lcc|}
\hline Site & Number of patients & Percentage \\
\hline Right breast & 48 & $48 \%$ \\
\hline Left breast & 50 & $50 \%$ \\
\hline Both breast & 2 & $2 \%$ \\
\hline Total & 100 & $100 \%$ \\
\hline
\end{tabular}

Table 3: Breast cancer patients in relation to location of lump.

\begin{tabular}{|lcc|}
\hline Quadrant & Number of patients & Percentage \\
\hline Upper outer & 63 & $63 \%$ \\
\hline Lower outer & 12 & $12 \%$ \\
\hline Upper inner & 10 & $10 \%$ \\
\hline Lower inner & 3 & $3 \%$ \\
\hline Central & 12 & $12 \%$ \\
\hline Total & 100 & $100 \%$ \\
\hline
\end{tabular}

Table 4: Clinical stage at presentation of patients in present series.

\begin{tabular}{|c|c|c|}
\hline \multicolumn{3}{|c|}{ Number of patients } \\
\hline Stage I & 5 & $5 \%$ \\
\hline Stage II & 42 & $42 \%$ \\
\hline Stage III & IIIB & $50 \%$ \\
\hline Stage IV & 3 & $3 \%$ \\
\hline Total & 100 & $100 \%$ \\
\hline
\end{tabular}

Table 5 : Histological types of breast cancer encountered in present series

\begin{tabular}{|lcc|}
\hline \multicolumn{2}{|c|}{ Number of patients } & Percentage \\
\hline Infiltrating ductal carcinoma & 85 & $85 \%$ \\
\hline Infiltrating lobular carcinoma & 8 & $8 \%$ \\
\hline Medullary carcinoma & 4 & $4 \%$ \\
\hline Mucinous carcinoma & 2 & $2 \%$ \\
\hline Paget's disease & 1 & $1 \%$ \\
\hline Total & 100 & $100 \%$ \\
\hline
\end{tabular}

\section{Discussion}

Breast cancer is the most frequent cancer in female, both in developed and developing regions and ranks second overall only to lung cancer (7). The present study has provided information about the clinicopathological aspects of the breast cancer in patients from this region. Breast cancer can occur at any age, but rare in patients younger then 25 years and over 80 years; the peak incidence is between 45 years and 60 years (8). The majority of the patients in this study are in the age group of 41 years to 60 years. All patients in this study presented with a lump in the breast with slightly left side dominance. Breast cancer most frequently involves the upper outer quadrant $(60 \%)$ followed by $12 \%$ in both central zone and upper inner quadrant , $10 \%$ In lower outer quadrant, $6 \%$ in lower inner quadrant (9). The data regarding the location of lump in the breast cancer patients from our study is in line with that reported by R K Gange et al.(10). They studied 108 cases and observed that the location of the lump was in upper outer quadrant in $48 \%$ cases, lower outer quadrant in $10 \%$ cases, lower inner quadrant in $12 \%$ cases and central quadrant in $12 \%$ cases. Infiltrating ductal carcinoma (85\%) was the most common histological type in the present study. Similar observation have been reported by Haque R et al.(11) with $75 \%$ cases being infiltrating ductal carcinoma in their study and Gupta JC et al.(12) with 91.1\% cases of infiltrating ductal carcinoma in their study. Baptist SJ et al.(13) reported $81.67 \%$ cases of infiltrating ductal carcinoma whereas Srivastava V et al.(14) observed $83.6 \%$ cases of infiltrating ductal 
carcinoma in their study. All the cases were graded into clinical stage at presentation . Grade III breast carcinoma was the most common type $(50 \%)$ in the present study. Srivastava V et al. have reported stage II $(62.3 \%)$ as the most common clinical stage at presentation. Also, Haque R et al. have reported stage II(46.4\%) as the most common clinical stage at presentation. The study has its limitations which include an observational and descriptive study design. Also, the sample size is relatively small. However, it provide valuable information regarding the clinico-pathological aspects of breast cancer patients from rural areas .

\section{Conclusion}

The incidence of breast cancer in India is increasing and basic education and awareness of the women's health, self breast examination, and clinical breast examination may help increasing awareness and help to identify breast cancer at early stage in developing Countries.

\section{References}

[1] Mahapatra M, Satyanarayan S . Evaluation of clinico-pathological findings of breast carcinoma in a general hospital in Southern India . Indian J Cancer 2013;50:297-301.

[2] Chandra A B . Problems and prospects of cancer of the breast in India . J Indian Med Assoc 1979;72:43-46.

[3] Kuraparthy S, Reddy KM, Yadagiri L A, Yutla M , Venkata P B, Kadaini S V et al.. Epidemiology and patterns of breast care for invasive breast carcinoma at a community hospital in Southern India . World J Surg Oncol 2007; 5 : 56-60.

[4] Chopra R. The Indian Scene. J Clin Oncol $2001 ; 19: 106-111$.

[5] Kulkarni S S , Kulkarni B B , Vandana T, Kulkarni S M and Kadakol G S , Modak H et al.. Expression profiling of breast gene in familial breast Cancer in India . Afr J Biotechnol 2012;11:9123-9126.

[6] Hortobagyi G N , J de la Garza Salazar, K Pritchard, D Amadori and R Haidinger et al.. The global breast cancer burden : Variations in epidemiology and Survival. Clin Breast Cancer 2005 ; 6: 391-401.

[7] Saha K, Roychowdhury G, Chattopadhya B K. Clinico-pathological study of breast carcinoma : A prospective two- year study in a tertiary care hospital . Clin Cancer Invesig J $2013 ; 2: 34-40$.

[8] Ellis I O , Pinder S E, Lee A H, Elston C W . Tumors of the breast. In: Fletcher C D, editor . Diagnostic histopathology of tumors . $2^{\text {nd }}$ ed, Vol 1. New york ( N K), USA : Churchill Livingstone; 2000 .p. 865-921.

[9] Sainsbury R. The breast . In : Williams N S , Butstrode C J , O'Connell R R, editors . Bailey and Love's short practice of Surgery . $25^{\text {th }}$ ed London, U K: Hodder Arnold ; 2008 . p. 827-848.

[10] Gange R K, Bothra V C , Panda S K . Cancer of the breast, a five year review at the Mahatma Gandhi Hospital , Jabalpur . Ind J Surg $1982 ; 44: 347-350$.

[11] Haque R , Tyagi S P, Khan M H, Gahlaut V Y S . Breast lesion : A clinicaopathological study of 200 cases of breast lump . Ind J Surg $1980 ; 42: 419-425$.

[12] Gupta G C , Munjal J S ,Raman A, Gandagule V N , Panda P k . Breast lumps in Jabalpur area . Ind J Surg 1983 ; 45 : $268-273$.

[13] Baptist S J , Thomas J A, Kothare S N . Lesions of the breast. J Ind Med Assoc 1983; 61 : 127-131.

[14] Srivastava V, Wahi K, Gupta A K, Mittal V P, Rajvanshi V S . Clinicopaological study of malignant breast neoplasms with special reference to cellular enzymatic activity . Ind J Cancer $1976 ; 13: 220-226$. 